\title{
Modular Approach to Technical Risk Management in Product Lifecycle Management
}

\author{
Roberto RIASCOS $^{\mathrm{a} 1}$, Tomislava MAJIĆ ${ }^{\mathrm{b}}$, Egon OSTROSI ${ }^{\mathrm{c}}$ and Josip STJEPANDIĆ ${ }^{\mathrm{d}}$ \\ ${ }^{a}$ Roche Diabetes Care GmbH, Germany \\ ${ }^{b}$ Croatian Academy of Sciences and Arts in Diaspora and Homeland (HAZUDD), St. \\ Gallen, Switzerland \\ ${ }^{c}$ ERCOS/ELLIADD EA4661, Univ. Bourgogne Franche-Comté, UTBM, F-90010 \\ Belfort, France \\ ${ }^{d}$ PROSTEP AG, Germany
}

\begin{abstract}
The current trend in product development is toward usage and integration of different advanced technologies which are increasingly embedded in a comprehensive PDM system as a company-wide information back-bone. With such an approach, the transparency is increased and many business processes accelerated. While modularization is a mega-trend, the modular approach is also used to align development processes with the workflows in PDM. The goal of an effective risk management system is to allow continuous business running and achieving the goals of an organization. In order to achieve this, it is necessary, as far as it is possible, to identify and to analyze risks the organization is confronting and to evaluate their effects on the business. In this paper, an approach is presented on how to integrate the technical risk management in Product Lifecycle Management by definition of an additional software module and its implementation.
\end{abstract}

Keywords. Modular Design, Risk Management, Configuration Management, Product Lifecycle Management

\section{Introduction}

Developed within a tight timeframe under fulfilment of challenging requirements, the modern product could easily suffer insufficient function and performance. That is an inherent circumstance which occurs in the enterprise's activities at all levels, what is called risk [1]. Because of the significant potential impact of these risk factors on business results and the inability to be fully controlled by the business, risk analysis is an important discipline within strategic and operational management of the enterprise which supposes the completion of the whole cycle of risk assessment [2].

Certainty is a state in which there is only one possible outcome of a decision. In reality, complete information and total certainty in the economy are very rarely encountered. In any case, neither economic life as a whole, nor particular economic processes, and in that context processes that occur in basic economic units such as a

\footnotetext{
${ }^{1}$ Corresponding Author, Email: roberto.riascos@roche.com.
} 
company or household, cannot be fully considered without taking into account uncertainty and risk [3].

Risk is the state in which the decision has more than one possible outcome and in which the probability of each specific risk is known or can be assessed. The likelihood of any possible outcome can be assessed from an earlier experience or from a market study. The greater the variability (ie the higher the number and the range) of the possible outcomes, the higher the risk is associated with the decision or the action [3].

Uncertainty is a state when a decision has more than one possible outcome and in which the probability of the occurrence of each specific outcome is unknown or even meaningless. This may be due to insufficient information from the past or the instability of the structure of the variables [3].

Neglecting risk is one of the biggest causes of bad decisions. Although the risk is an integral part of the business, it is necessary to know how to manage the risk by making informed decisions based on modern analyzes of quality data. Understanding data is extremely important, mostly because it helps to identify and understand potential opportunities, but also to minimize the risk of entry into business ventures that do not have coverage. Without the insufficient understanding of the data and the appropriate methods for data analysis, the most common results can be detrimental to the company [3].

The paradigm of modularity has emerged as a relevant way to meet customer requirements with a wide range of variety and customisation of products, from unique to standard ones. The modularity area is becoming increasingly multidisciplinary, which implies holistic and articulated concurrent engineering approaches [4]. Modularity can intersect technical aspects with the business aspects. The use of modular technology has wide-reaching implications for any design and development company that undertake to use this paradigm. In the context of engineering, modularity combines technical aspects with business aspects, both from a qualitative and a quantitative viewpoint (Figure 1) and can be also applied to methods and processes.

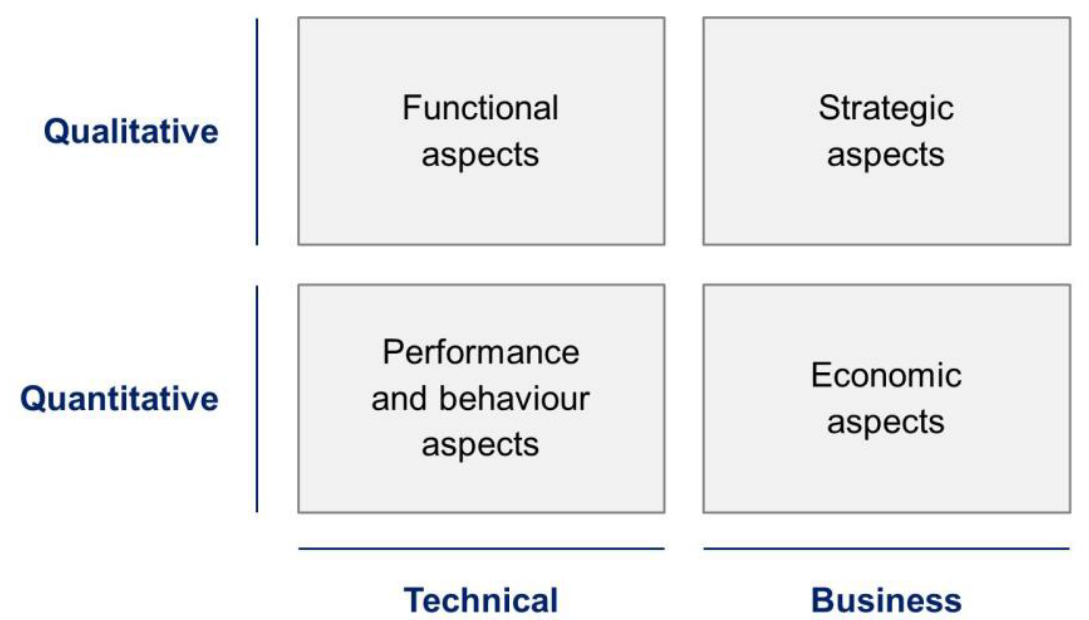

Figure 1. Aspects and viewpoints of modularity [4].

The remainder of this paper is structured as follows: in Section 1 the background is given, followed by the description of the solution concept in Section 2. In Section 3 the implemented solution is shown, Section 4 summarizes the conclusions and outlook. 


\section{Background}

\subsection{Modularity in products and processes}

The modular design considers functions, properties and interfaces of product constituents. Standard interfaces make parts interchangeable, thereby reducing the expenditure for the combination of different product constituents.

In the domain of tangible, assembled artefacts, a product system is modular to the extent that its separable components, or modules, are combinable [5]. Autonomy or independence towards external, dependence towards the internal is an important characteristic of modules. Technically, products can be understood as a network of components that share technical interfaces (or connections) in order to function as a whole. Minimization of interactions with external components and maximization of interactions between the components within the module are thus principles for finding modules. Actually, the life-cycle of a module is confined to predefined scenarios that depend on its interfaces and its connections. Technically, it can be expressed with three measures: (a) how components share direct interfaces with adjacent components, (b) how interfaces may propagate to nonadjacent components in the product, and (c) how components may act as bridges among other components through their interfaces.

In general, from a management perspective, modularity can be seen as a business strategy for efficient design and structuring of complex products, procedures and services with the objective to rationalize the enterprise. By now, modularity can be considered a basic development methodology inside the product strategy for a variety of technical Product Service System designs [6][7]. Modularity seems counter-productive when selective distinctive features are the reason to buy a product. When customers focus on elements like styling, haptics, or specific colours, creative freedom is necessary. In such cases, modular design is not applicable, because investments in modular design outweigh the efforts to create a user-specific product of which the number is often very small. The integration of different product variants does not come with any monetary benefits if it is not organized through a holistic controlling approach [8]. The holistic approach enables the assessment of modular product families as well as their holistic management based on the new modularity-balanced-score-card (M-BSC). Additionally, the different perspectives from production, development, marketing sales and services need to be integrated. Cost schemes of modular products can also be established by decomposing the product family into generic modules to support cost calculation.

The concept of an intelligent product should maximize the design space of architects and system designers. How to design intelligent modules is an important issue related to the design of intelligent products. Thus, the development of intelligent multidisciplinary collaborative and distributed platforms can better handle the modularity and variant management problem. The multi-agent paradigm has the potential to respond to this challenge and to pave the way for the introduction of innovative technologies in a dynamic environment characterized by important changes and evolution.

The design of a modular product is considered to resolve a system-based interdependency problem. The modular design should be the result of a coherent and rational design process, where the options, modular or integral, are explored early, in response to technical constraints and the set of requirements. A task in modularity assessment is also the issue of increasing the effectiveness of modularity. Modularity should be supported by all down-stream business processes (e.g. change management, risk management). 


\subsection{Technical risk management}

Risk management is a process that identifies, assesses and processes risks by using consistent and repeatable procedures to base the report on and to monitor risky activities. Risk management does not endeavour to eliminate risks, but create an environment in which optimal business decisions can be made taking into account the identified risks and the consequences that they can cause [3].

Once the risks are identified and passed through the above procedures, it is very important to choose the appropriate technique that will effectively remove or control exposure to risks [3].

After carrying out a risk assessment and an analysis of the consequences, organizations can use some of the basic techniques related to reducing the negative consequences of risks. Some techniques can produce the desired results, others manage the best through a combination depending on the size and type of exposure [3].

In the domain of technical products, different approaches and methods are used in practice for dealing with the technical risks in product development [9]. For a medical device, while the main objectives are the patient health and human life, the process risk management must run through the lifecycle of the medical device to avoid potential hazards.

ISO 31000 is a basic standard for risk management (Figure 2) [10]. It should not serve as the basis for certification, but should guide action for effective and efficient risk management, regardless of the domain of an organization. It addresses every organization that has to master risks. In contrast, ISO 14971 is the standard for "Application of risk management to medical devices" [11]. It describes a risk management process designed to ensure that the risks associated with medical devices including in vitro diagnostic (IVD) medical devices, are known and controlled and that they are acceptable in comparison to the benefits [12]. The requirements of ISO 14971 are applicable to all stages of the life-cycle of a medical device [13]. Both standards are implemented by using appropriate methodologies such as FMEA.

The Failure Mode and Effects Analysis (FMEA) is an analytical method in the area of reliability engineering used during development and planning to analyze and avoid potential risks that are applied at system, design and process levels [14]. During the planning phase, the FMEA should detect potential errors during the development of a product and avoid them by taking suitable measures. It evaluates and mitigates the potential malfunctions in a system, process, design or service according to their significance for the customer, their probability of occurrence and their probability of discovery, each with a key figure [14]. Furthermore, with the help of the FMEA, it is possible to systematically collect and make available existing knowledge of error contexts and quality influences.

FMEA also serves to systematically analyze existing defect images and thus enables product or process improvement after the planning phases have already been completed. The systematic approach is supported by forms to document the results [15]. A distinction is made between design, process and system FMEA, which share a similar approach. It is an effective quality improvement and risk assessment tool widely used in practice [16]. FMEA and ISO 14971 risk analysis receive the most attention from manufacturing companies; therefore, FMEA is used as a prevention and improvement tool to analyze the risks in the medical product development process [14]. The risk during each stage and the associated consequences related to its occurrence were discussed with the development team. Calculation of risk priority numbers (RPN) for identified risks as 
prescribed by ISO 14971 (2012) guidelines for risk analysis is one noticeable step in FMEA to prioritize the failure modes. RPNs are determined by an evaluation of three factors: occurrence (O), severity (S) and detection (D) [14].

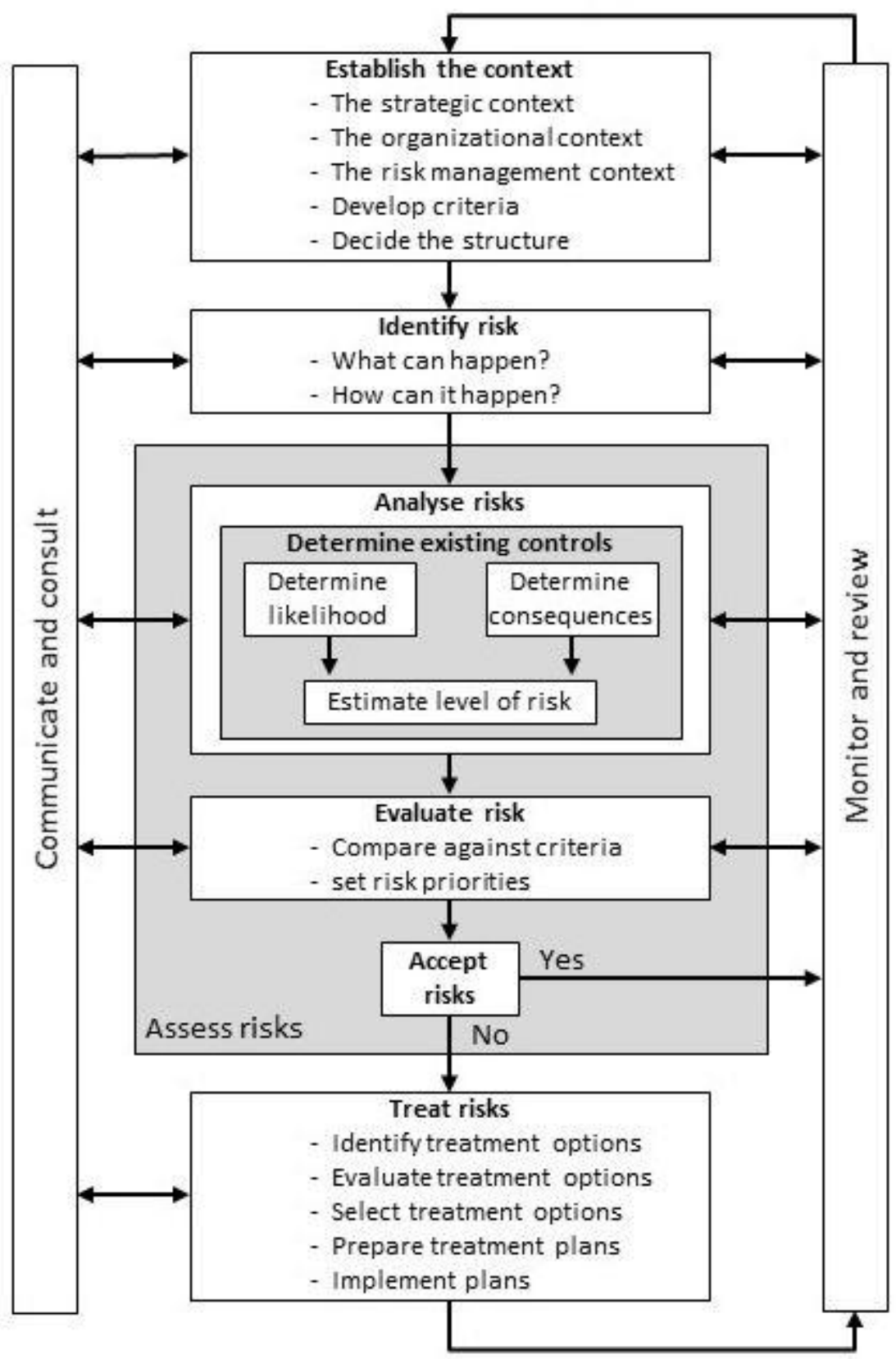

Figure 2. ISO 31000 compliant Risk Management Framework. 


\subsection{Product Lifecycle Management (PLM)}

Product Lifecycle Management (PLM) is widely understood as concept for the creation, processing, storage, and retrieval of data, information and, ideally, knowledge throughout the lifecycle of a product from its conceptualization or inception to its disposal, recycling or recovery [17]. PLM is seen in the industry as one of the core concepts to fulfil a number of business requirements in the manufacturing industry with respect to the completeness, high transparency, rapid accessibility and high visibility of all product data during a product's lifecycle [18]. Those requirements also are related to financial aspects like cost management and revenue growth, to the product itself like innovation, competitive functionality, time to market, quality and high productivity, and to regulatory aspects as compliance, product risk management and documentation. PLM is implemented by deploying IT systems like Product Data Management (PDM) systems and induces a high level of interoperability of related applications. With PLM industrial companies attempt to gain advantages in shorter cycles, lower costs, better quality by avoiding errors and misunderstanding [17].

In modern PDM systems, the overall structure of a modular product is mapped in a generalized product structure [19][20]. Alternative or optional items are initially managed in the database of PDM systems in the same way as all other items, i.e., items as master records with corresponding attributes. Differences to the usual article management arise only in the structuring of the product in the form of bills. Through the use of variants in product structures, PDM systems are able to manage order neutral BOMs with varying and optional positions. This approach is beneficial for product development, and less for production and accompanied departments, because explicit BOMs are needed for each product variant to be produced. Furthermore, there is a risk that data management is very complicated, while compromising the performance of the system needs to be tolerated, especially when a large number of product variants need to be managed. To resolve these conflicts, modern PDM systems are extended by the variant manager module [21]. In the base module, all master data (parts, structures and processes) are managed. In the case of variants, explicit ones are derived by the configuration and clone modules. For risk management, a coherence of the single-partrelated risk estimation (e.g. FMEA) with a certain product variant is necessary. This can be fulfilled by an application which conducts FMEA calculation for each part in the product structure and, afterwords, generates a product FMEA parsing each variant by using appropriate product FMEA reports.

Under the term mass customization, a business strategy is defined that utilizes modular design for complex offerings of products and services that are configured on demand to achieve the best fit with customer-specific needs [22]. The product structure of customized products must be thoroughly adjusted for specific customization options by adopting entirely individual components that are specifically created beside standardized and configurable modules. Generally, a fixed and a variable area of product structure can be identified, in which mandatory and optional spaces are foreseen for individual implementation. Product customization is usually supported by configuration systems. Generic conceptual procedures for designing such a system are important for mass customization [23]. These procedures involve analysis and redesign of the business processes, analysis and modelling of the company's product portfolio, selection of configuration software, programming of the software, and implementation and further development of the configuration system towards Product-Service System (PSS). Integration of risk management supporting methods like FMEA is also possible. 


\section{Solution concept}

Technical risk management, modularity and PLM are related fields of engineering that can ideally be combined in a process chain and implemented as a technical solution by a software module which works on PDM data. Following to the overall concept of PLM, the demand is given last but not least by regulatory rules [24]. We draw a solution which builds the product risk line based on risk case and supportive information (Figure 3).

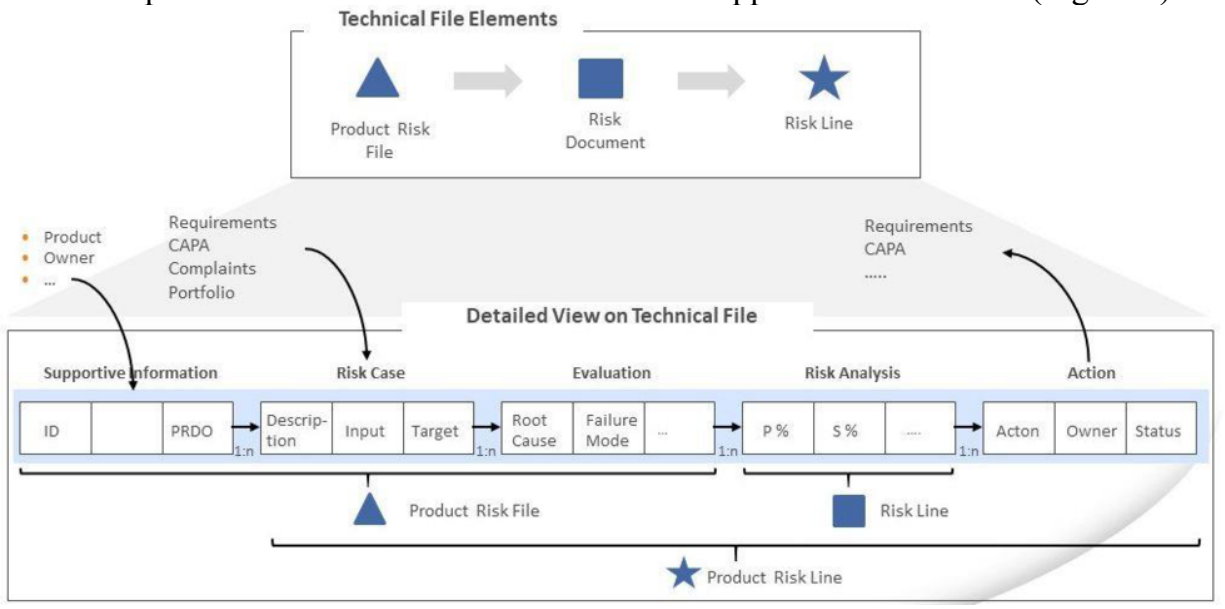

Figure 3. Data model for Product Lifecycle Management based risk management.

Basically, a risk case is initiated by the product owner and consists of the target, the input and the description and, subsequently, is the subject of risk evaluation. The main drivers are requirements, CAPA (Corrective and Preventive Action), complaints and portfolio. A risk case discovers a 1:n relationship to an evaluation which consists of the root cause, the failure mode and failure mechanism.

Risk evaluation yields a 1:n relationship to risk analysis which consists of probability, severity, occurrence and detection. Based on the risk analysis, appropriate actions can be incurred and assigned to an owner. Each action has a status and is related to the aforementioned main drivers. In such a way, a circular flow with four items of the product risk line is built.

This data model easily allows decomposition of the risk chain. Modularity is achieved by partitioning information into three categories: Architecture, Interfaces and Standards. The architecture specifies system modules and their functions. Interfaces describe the interaction of modules. Standards test a module's conformity to the design rules and compare the performance of competing modules. Usually, engineers use decompositions to describe a product or process. Describing a process like risk management leads to structuring the process in terms of its structural or functional properties. The structural and functional decomposition can again be decomposed using some new engineering properties leading to new sets of decompositions. By embedding this process into PDM system, singular items can be assigned to the nodes in the product structures. This facilitates the evaluations for certain trees in the product structure (e.g. specific variant).

Figure 4 shows decompositions related to product risk management in PDM system which allow a high level of transparency and provide several possibilities for monitoring and tracking of risk cases. 


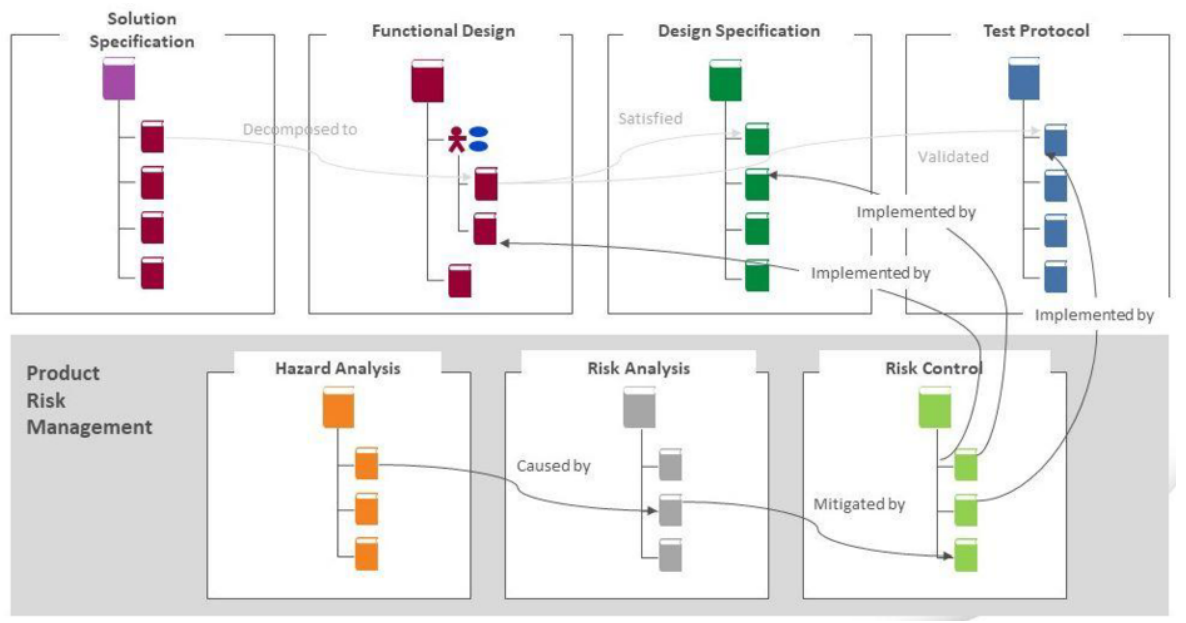

Figure 4. Solution model.

\section{Implemented solution}

This concept is realized as an early implementation as a Product Risk Management (PRM) module of ThingWorx Navigation within the PDM system Windchill. It is fully embedded in the typical workflows like release and change management.

The application provides several roles (risk manager, FMEA moderator, product owner, user, administrator) as well as several workflows (create, edit, delete, administration, reporting). The main benefit of this solution is the instant availability of needed information. For example, a FMEA Moderator/Risk Manager is able to easily have an overview of the status and the type of controls defined in a FMEA/PRA so that they can drive implementation of those controls.
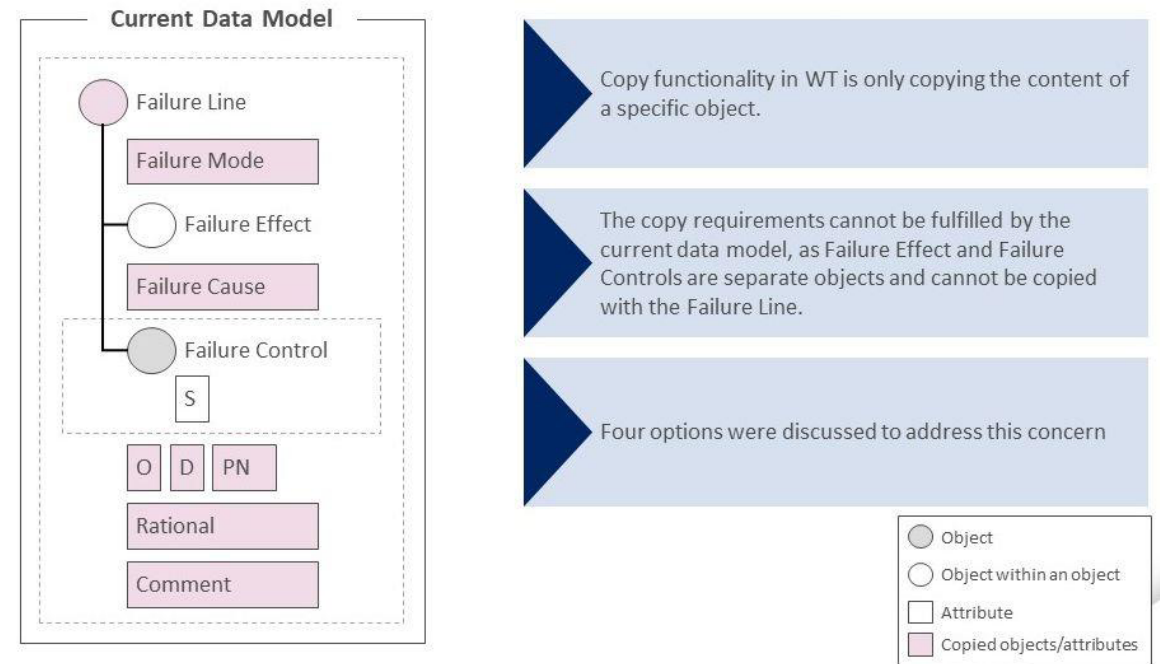

Figure 5. Current concerns regarding the data model. 
One of the obstacles identified in the productive use is depicted in Figure 5. It belongs to the copy function which is frequently used when a similar case needs to be derived from the existing one. Windchil allows the copy function for the content, and not for the linked object itself. The copy requirements cannot be fulfilled by the current data model, as Failure Effect and Failure Controls are separate objects and cannot be copied with the Failure Line. Four options were discussed to address this concern and will be implemented in the maintenance mode.

\section{Conclusions and outlook}

Theory and practice have confirmed that a systemic and consistent approach to risk management can minimize the risks that business activities carry with them. Management must be aware of all the threats that threaten the company or the start of the product development, leaving the investor indebted. Knowing the risks, the manager can create a good risk management program, because the risk protection is extremely important and a necessary part of the company's business.

This paper presented a modular approach for technical risk management in PLM for medical devices. The usage and integration of different technologies and modules (e.g. application of analytics and evaluation [25]) into comprehensive PDM systems, is the current trend in the manufacturing industry. Development of intelligent models and intelligent tools on the one hand, and the development of intelligent modular products, on the other, which can communicate and cooperate between them, need holistic and intelligent engineering approaches which also include risk consideration based on ISO 14971. These approaches can offer the possibility of the design of self-sustainable models and self- sustainable products. Thus, the development of intelligent collaborative and distributed platforms within Product Lifecycle Management can better handle modularity and risk management [26]. The presented solution has the potential to respond to this challenge and to pave the way for the introduction of innovative technologies in a dynamic environment characterized by important changes and evolution [27].

Viewing a transdisciplinary process from a system's perspective may help to identify a subsystem or aspect system, that requires specific attention while taking into account the context in which this system exists [28]. In this way, the impact of the system context on the system under consideration as well as the impact of changes made to the system on its context can be better identified and taken into account because we still live in the information age, where an instant availability of important information is the prerequisite for a successful business.

\section{References}

[1] T. Aven, Foundational Issues in Risk Assessment and Risk Management, Risk Analysis, Vol. 32, No. 10, 2012, pp. 1647-1656.

[2] T. Aven and E. Zio, Foundational Issues in Risk Assessment and Risk Management, Risk Analysis, Vol. 34, No. 7, 2014, pp. 1164-1172.

[3] B. Pongrac, T. Majić, Business Risk Management, Technical Journal, Vol. 9, 2015, No. 1, pp. 94-98.

[4] J. Stjepandić, E. Ostrosi, A.-J. Fougères, M. Kurth, Modularity and Supporting Tools and Methods, in: J. Stjepandić et al. (eds.): Concurrent Engineering in the $21^{\text {st }}$ Century: Foundations, Developments and Challenges, Springer International Publishing Cham, 2015, pp. 389-420. 
[5] F. Salvador, Toward a Product System Modularity Construct: Literature Review and Reconceptualization. IEEE Trans. Eng. Manag., 2007, Vol. 54, pp. 219-240. https://doi.org/10.1109/TEM.2007.893996.

[6] J. Sun, N. Chai, G. Pi, Z. Zhang and B. Fan, Modularization of Product Service System Based on Functional Requirement, Procedia CIRP, 9th CIRP IPSS Conference: Circular Perspectives on PSS 64, 2017, pp. 301-305. https://doi.org/10.1016/j.procir.2017.03.038

[7] M. Tinnilä, M. Lipponen, M. Rajahonka and A. Bask, The concept of modularity: diffusion from manufacturing to service production. J. Manuf. Technol. Manag., 2010, Vol. 21, pp. 355-375. https://doi.org/10.1108/17410381011024331.

[8] M. Jung, Controlling modularer Produktfamilien in der Automobilindustrie, Deutscher Universitätsverlag, Wiesbaden, 2005.

[9] J.H. Klein, R.B. Cork, An approach to technical risk assessment, International Journal of Project Management, Vol. 16, 1998, No. 6, pp. 345-351.

[10] I.S. E DIN ISO 31000:2018-05 (2018) Risk management - Guidelines (ISO 31000:2018).

[11] I.S. EN ISO 14971 (2012) Medical devices. Application of risk management to medical devices (Standard for the application of risk management to medical devices).

[12] M.N. Teferra, ISO 14971 - Medical Device Risk Management Standard, International Journal of Latest Research in Engineering and Technology (IJLRET), 2017, Vol. 3, Issue 3, March 2017, pp. 83-87.

[13] D. Flood, F. McCaffery, V. Casey, R. McKeever and P. Rust, A roadmap to ISO 14971 implementation, Journal of Software: Evolution and Process, 2015, Vol. 25(5), pp. 319-336.

[14] M.S. Kirkire, S.B. Rane and J.R. Jadhav, Risk management in medical product development process using traditional FMEA and fuzzy linguistic approach: a case study, Journal of Industrial Engineering International, 2015, Vol. 11, pp. 595-611.

[15] X. Zhao and X. Bai, The Application of FMEA method in the risk management of medical device during the lifecycle, 2010 2nd International Conference on E-business and Information System Security, 22-23 May 2010, DOI: 10.1109/EBISS.2010.5473713, pp. 455-458.

[16] E. Caillaud, R. Crossland, D. Gourc, C. McMahon, L.A. Garcia, A Framework for a Knowledge-Based System for Risk Management in Concurrent Engineering, Concurrent Engineering: Research and Applications, 1999, 7 (3), pp. 257 - 267.

[17] L. Lämmer, M. Theiß, Product Lifecycle Management, in: J. Stjepandić et al. (eds.): Concurrent Engineering in the $21^{\text {st }}$ Century: Foundations, Developments and Challenges, Springer International Publishing Cham, 2015, pp. 389-420.

[18] C. Emmer, A. Fröhlich and J. Stjepandić, Advanced engineering visualization with standardized 3D formats, IFIP Advances in Information and Communication Technology, Vol. 409, Springer, Berlin Heidelberg, 2013, pp. 584-595.

[19] K. Baylis, G. Zhang and D.A. McAdams, Product family platform selection using a Pareto front of maximum commonality and strategic modularity, Research in Engineering Design, 2018, Vol. 29, pp. 547-563.

[20] H.P.L. Bruun, N.H. Mortensen, U. Harlou, M. Wörösch and M. Proschowsky, PLM system support for modular product development, Computers in Industry, 2015, Vol. 67, pp. 97-111.

[21] R. Riascos, J. Stjepandić, L. Levy and A. Fröhlich, Digital Mock-up, in: J. Stjepandić et al. (eds.): Concurrent Engineering in the 21st Century: Foundations, Developments and Challenges, Springer International Publishing Cham, 2015, pp. 355-388.

[22] F.T. Piller and M.M. Tseng, Handbook of Research in Mass Customization and Personalization, World Scientific Publishing, Singapore, 2010.

[23] D.T. Custódio, G.L. Roehe Vaccaro, F.L. Nunes, G. Vidor and L.D. Chiwiacowsky, Variant product configuration of industrial air handling units in a MTO environment, International Journal of Advanced Manufacturing Technology, 2018, Vol. 95, pp. 1025-1037.

[24] J. Hatcliff, E.Y. Vasserman, T. Carpenter and R. Whillock, Challenges of distributed risk management for medical application platforms, 2018 IEEE Symposium on Product Compliance Engineering (ISPCE), 14-16 May 2018, DOI: 10.1109/ISPCE.2018.8379270.

[25] R. Wallis, J. Stjepandić, S. Rulhoff, F. Stromberger and J. Deuse, Intelligent utilization of digital manufacturing data in modern product emergence processes, Advances in Transdisciplinary Engineering, Vol. 1, 2014, pp. 261-270.

[26] R.C. Beckett, H. Vachhrajani, Transdisciplinary Innovation: Connecting Ideas from Professional and User Networks, Journal of Industrial Integration and Management, Vol. 2, 2017, No. 4, 1750016.

[27] J.B. Mathiasen, R.M. Mathiasen, Practicing Transdisciplinary Engineering in a Global Development Context: The Transferring, Translating and Transforming Approaches, Journal of Industrial Integration and Management, Vol. 2, 2017, No. 4. 1750017, DOI: 10.1142/S2424862217500178.

[28] N. Wognum, C. Bil, F. Elgh, M. Peruzzini, J. Stjepandić and W.J.C Verhagen, Transdisciplinary systems engineering: implications, challenges and research agenda, International Journal of Agile Systems and Management, Vol. 12, 2019, No. 1, pp. 58-89. 